\title{
Valoração Econômica dos Efeitos Internos da Erosão: Impactos da Produção de Soja no Cerrado Piauiense
}

\author{
Kerle Pereira Dantas ${ }^{1}$ \\ Maria do Socorro Lira Monteiro ${ }^{2}$
}

\begin{abstract}
Resumo: Objetivou-se mensurar economicamente os custos internos da área de produção de soja no cerrado piauiense, sob os sistemas de plantio direto e convencional, causados pelo processo de erosão, nas safras de 2000/2001 e de 2007/2008. O procedimento metodológico centrou-se no levantamento bibliográfico e estatístico de dados secundários e na aplicação do método do custo de reposição de nutrientes, no intuito de verificar qual o impacto econômico da degradação do solo na região. Por meio da pesquisa constatou-se que, em ambos os períodos de safras e sistemas de plantios analisados, os custos de reposição foram expressivos, representando, em média, $2,9 \%$ do valor total da produção de soja. Na safra 2000/2001, os custos por hectare foram de R $\$$ 22,96 e R $\$ 21,93$ para os plantios convencional e direto, respectivamente. Para a safra 2007/2008, os custos foram de $\mathrm{R} \$ 22,40$ e $\mathrm{R} \$ 21,20$, respectivamente. Portanto, esta configuração explicitou a relativa estabilidade do valor da perda de solo no período de análise, haja vista apresentar reduzido decréscimo na safra 2007/2008. Logo, inferiu-se que o uso do sistema de plantio direto no cultivo de soja no cerrado piauiense não somente proporcionou vantagens econômicas, mas, sobretudo, contribuiu para a sustentabilidade do agroecossistema.
\end{abstract}

Palavras-chaves: Erosão; valoração econômica; cerrado piauiense.

1 Economista e Mestre em Desenvolvimento e Meio Ambiente da Universidade Federal do Piauí. E-mail: kerledantas@hotmail.com

2 Professora do Departamento de Ciências Econômicas da UFPI, Mestrado e Doutorado em Desenvolvimento e Meio Ambiente da Universidade Federal do Piauí.

E-mail: socorrolira@uol.com.br 
620 - Valoração Econômica dos Efeitos Internos da Erosão: Impactos da Produção de Soja no Cerrado Piauiense

Abstract: The present article aimed to measure the economic costs of the domestic production soybean area in the cerrado (one type of vegetation in Brazil) of Piauí, in the systems of conventional and tillage, caused by the process of erosion in the 2000/2001 and 2007/2008 seasons. It analyzes the historical process of international integration of the Brazilian economy through the primary-exporting model, emphasizing the intensive use of natural resources as factor of competitiveness, characterized by the occupation and use of Brazilian cerrado and based on the soybean production and examined the consequences and risks to the biome arising from that process. The methodological procedure focused on the literature review and statistical from secondary data and the application of the replacement cost of nutrients method, to verify the economic impact of soil degradation in the region. Through the research, it was found that in both periods of crop and planting systems analyzed, costs of replacement were significant, representing, on average, 2.9 percent of the total soybean production. In the 2000/2001 season, the cost per hectare was 22.96 reais and 21.93 reais for conventional tillage and direct planting, respectively. While in the 2007/2008 crop, harvest costs were 22.40 reais and 21.20 reais, respectively. Therefore, this configuration explained the relative stability of the value of the loss of land during the period under review, once having presented low decrease in the 2007/2008 season. Therefore, it is inferred that the use of the system of tillage in the soybean planting in the cerrado of Piauí not only has economic advantages, but above all, has contributed to the sustainability of the agro ecosystem.

Key-words: Erosion; economic valuation; cerrado of Piauí.

Classificação JEL: Q510 Valuation of Environmental Effects.

\section{Introdução}

A ocupação do cerrado piauiense, alicerçado no cultivo de soja, apesar de intensificar-se a partir da década de 90, integrou o mesmo modelo de modernização agrícola, iniciado e capitaneado pelo governo brasileiro duas décadas antes. A ocupação agrícola da região assentada na monocultura da soja e no tripé grandes extensões de terras, mecanização e adubação química, provocou impactos ambientais, como o desmatamento, o aumento de emissões de gases de efeito estufa, a perda de patrimônio genético e de habitat de espécies 
nativas, a contaminação dos solos e das águas com resíduos de fertilizantes e agrotóxicos e, principalmente, a aceleração das taxas de erosão.

Segundo Marques (1998), a erosão dos solos encerra efeitos internos e externos à área de produção. Os internos estão associados à perda da eficiência da produção agrícola, e os externos são apreendidos por agentes econômicos que sofrem fundamentalmente com o processo de assoreamento dos recursos hídricos, cujas despesas não estão incluídas nos custos privados do produtor/ degradador.

Em face do exposto, este artigo objetiva mensurar economicamente os efeitos internos da degradação ambiental causados pelo processo de erosão, a partir do custo de reposição dos nutrientes perdidos pelo solo agrícola do cerrado piauiense nas safras 2000/2001 e 2007/2008. Assim, os valores econômicos identificados servirão para subsidiar a formulação de políticas públicas que visem não somente o controle da erosão dos solos agrícolas, mas também da qualidade ambiental dos demais recursos naturais. Entretanto, este tipo de abordagem não mensura os danos causados a outros bens e serviços ambientais envolvidos, como a perda da biodiversidade e da qualidade dos recursos hídricos.

\section{A inserção da soja no cerrado piauiense}

Em consonância com Diniz (2007), o Cerrado, por ser o segundo maior bioma brasileiro, superado em área apenas pela Amazônia, ocupa $21 \%$ do território nacional e é considerado a última fronteira agrícola do País. O termo Cerrado é comumente utilizado para designar o conjunto de ecossistemas (savanas, matas, campos e matas de galeria) que começam na região Sudeste e estendem-se para Centro-Oeste, Norte e Nordeste, com clima estacional, caracterizado por período chuvoso de outubro a março, e seco, de abril a setembro, conhecido como veranico.

De acordo com a Fundação Cepro (1992), o cerrado piauiense é o quarto mais importante do Brasil e o primeiro do Nordeste, ocupando área de 11,86 milhões de hectares, o que corresponde a $46 \%$ da área do Piaú, equivalendo a $5,9 \%$ do Cerrado brasileiro e a $36,9 \%$ do nordestino. Do total, $70 \%$ correspondem à área de domínio e os $30 \%$ restantes compreendem a vegetação de transição entre a Caatinga e o Cerrado, estendendo-se por vários pontos, de norte a sul do estado, sendo a maior concentração localizada na região sudoeste e extremo-sul. Estima-se que em torno de 10\% desse ecossistema seja ocupado e utilizado com projetos agropecuários. 
622 - Valoração Econômica dos Efeitos Internos da Erosão: Impactos da Produção de Soja no Cerrado Piauiense

Nas ultimas três décadas do século XX, a região inseriu-se no processo de modernização da agropecuária capitalista, cujas expressões primordiais assentaram-se na incorporação da ciência e tecnologia ao processo produtivo, na imigração de grupos econômicos hegemônicos, como a Bunge Alimentos S.A e na mobilização de agricultores empreendedores capitalistas de outras regiões do País.

Esta nova configuração produtiva foi embasada, por um lado, na significativa expansão do cultivo de soja e, por outro lado, na redução da produção de milho e arroz, como apresentado no Gráfico 1.

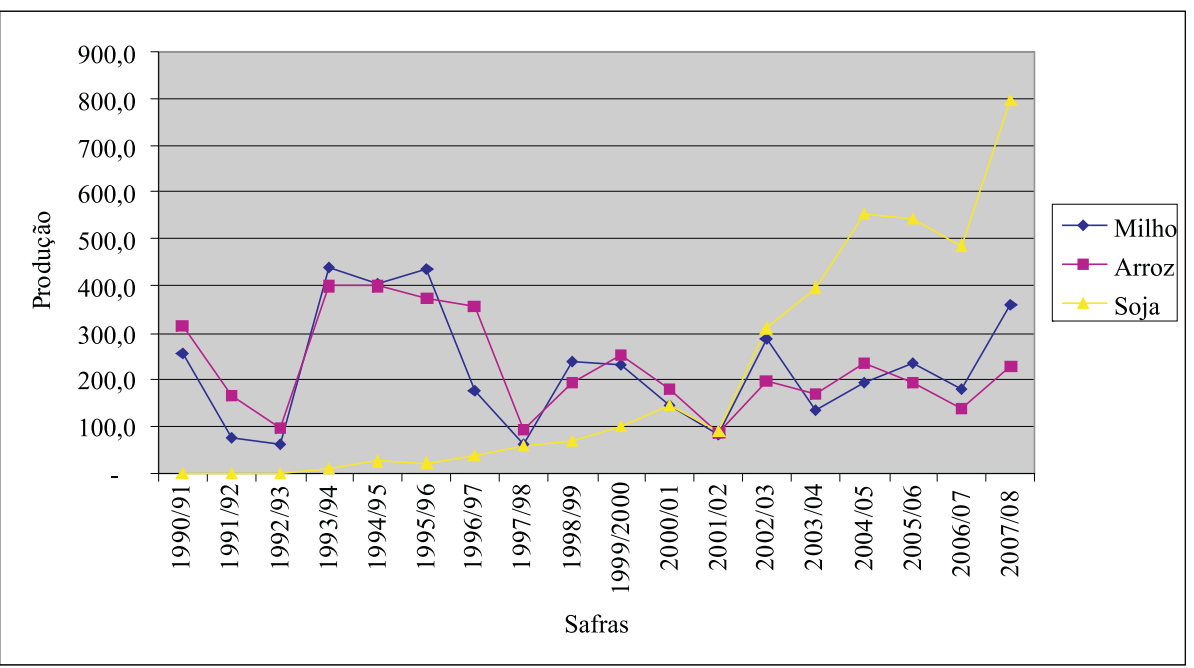

Gráfico 1. Produção de milho, arroz e soja no Piauí, safras 1990/1991 a 2007/ 08, em mil toneladas

Fonte: Elaboração própria a partir dos dados da Conab (2008).

Por meio da série histórica constante no Gráfico 1, visualizou-se que a produção da soja no cerrado piauiense acompanhou a cronologia dos fatos relevantes para a consolidação do agronegócio na região, isto é, a efetiva instalação dos produtores na década de 90 e da Bunge Alimentos S.A em 2002. A produção da leguminosa na safra 1990/1991 foi incipiente; porém, com a progressiva migração de produtores agrícolas ao Piauí, entre as safras 1991/ 1992 e 2000/2001, a produção cresceu celeremente, atingindo inclusive a taxa média de crescimento de $35,2 \%$ ao ano. Ressalta-se que o boom na produção ocorreu simultaneamente à instalação da fábrica de esmagamento de soja, em 


\section{Kerle Pereira Dantas \& \\ Maria do Socorro Lira Monteiro}

Uruçuí, devido ao fato de a Bunge Alimentos S.A ter financiado a produção e acrescido a demanda, atuando no mercado como monopsonista. Outrossim, verificou-se que, entre as safras 2002/2003 e 2007/2008, a taxa média de crescimento elevou-se para 59,6\% ao ano, apresentando recorde de produção na última colheita, de 795,7 mil toneladas.

\section{Materiais e métodos}

Os custos internos da erosão devem ser calculados com base nas transformações das perdas de solo em perdas de nutrientes, considerando-se a composição do solo. De acordo com Campos (2000, p. 17), “(...) do ponto de vista econômico, o custo da erosão não depende da quantidade física de terra perdida, mas dos efeitos econômicos dessas perdas", o que denota que os dados físicos demonstram a grandeza qualitativa do processo erosivo, mas não são suficientes para aferir as medidas econômicas dos impactos. Dessa forma, fazse premente conhecer o valor monetário do rendimento perdido, estimado através dos custos de reposição de nutrientes.

Sendo assim, com base em Marques (1998), expõe-se a equação ajustada de determinação dos custos internos:

\section{Custos internos $=(\mathbf{Q n} \times \mathbf{P n})+\mathbf{C a}+\mathbf{F B N}^{3}+(\mathbf{P p} \times \mathbf{Q p})^{4}$, em que:}

$\mathrm{Qn}=$ fertilizantes carreados pela erosão (tonelada);

$\mathrm{Pn}=$ preço dos fertilizantes $(\mathrm{R} \$)$;

$\mathrm{Ca}=$ custo de aplicação dos fertilizantes $(\mathrm{R} \$)$;

FBN = custo da fixação biológica do nitrogênio $(\mathrm{R} \$)$;

$\mathrm{Pp}=$ preço da produção agrícola $(\mathrm{R} \$) ;$

$\mathrm{Qp}=$ redução da produtividade de longo prazo devido à erosão.

\footnotetext{
3 Segundo Dobereiner (1989), o processo de reposição de nitrogênio nos plantios de soja difere dos procedimentos adotados para o fósforo, potássio e cálcio + magnésio, em função de exigir a Fixação Biológica do Nitrogênio (FBN). Trata-se de um processo bioquímico em que o nitrogênio atmosférico é incorporado às plantas por meio da inoculação das sementes com a bactéria específica, o que substitui totalmente a adubação artificial.

${ }_{4}$ Orientando-se por Marques (1998), diante da inexistência de informações sobre a redução da produtividade EM longo prazo, como no caso do presente estudo, reconheceu-se como verdadeira a hipótese de que a reposição de nutrientes é suficiente para a manutenção da produtividade. Portanto, atribuiu-se valor zero às variáveis Pp e Qp, tornando-as nulas para efeito de cálculo.
} 
624 - Valoração Econômica dos Efeitos Internos da Erosão: Impactos da Produção de Soja no Cerrado Piauiense

Para o cálculo da equação, após a obtenção dos valores da área plantada de soja na região estudada, dos índices de perda média de solo e do teor médio de nutrientes, faz-se necessário:

i) estimar a evolução das perdas médias de solo em tonelada por hectare ao ano, considerando-se o uso do solo no período sob investigação;

ii) dimensionar as quantidades de nitrogênio, fósforo, potássio e cálcio+magnésio carreados pela erosão em função das perdas físicas de solo, em toneladas por hectare ao ano;

iii) obter o equivalente em fertilizantes dos nutrientes perdidos na região em toneladas, por meio da mensuração da variável Qn;

iv) pesquisar os preços de mercado dos fertilizantes para o período, em reais por toneladas, para obtenção da variável Pn;

v) calcular os custos da Fixação Biológica do Nitrogênio para a área em estudo para obtenção da variável FBN;

vi) calcular os custos médios de aplicação dos fertilizantes para a região, em reais, para determinar a variável $\mathrm{Ca}$.

Ademais, para o cálculo das perdas econômicas oriundas da erosão, fazse premente salientar as técnicas de plantio adotadas, sob pena de os resultados diferirem substancialmente da realidade. Todavia, como não existem estatísticas precisas de área plantada por sistema de plantio no cerrado piauiense, duas hipóteses foram consideradas: 1) toda a produção de soja é realizada por meio do plantio convencional; 2) toda a produção de soja é implementada por meio do plantio direto. No intuito de realizar a análise comparativa da evolução do valor econômico da erosão na região, foram calculados os valores para as safras 2000/2001 e 2007/2008, ou seja, da primeira e última safras, relativos ao período da pesquisa.

Agrande dificuldade para a aplicação das técnicas de valoração ambiental centra-se na ausência generalizada de dados, principalmente quanto aos indicadores físicos de referência próprios de cada ecossistema. Logo, em virtude da inexistência de informações a respeito da área sob investigação, lançou-se mão de estudo de áreas com particular semelhança quanto ao tipo de solo (Latossolos) e cultura (soja) predominante na região, realizados por Dedecek et al (1986). 


\section{Resultados e conclusões}

Para o cálculo dos custos internos, é imprescindível mensurar preliminarmente a erosão de todo o cerrado piauiense decorrente da produção de soja. Destarte, o referido dado resultou do produto das perdas de solo, por hectare, sob sistemas de plantio, pela área ocupada com soja, como explicitado na Tabela 1.

Tabela 1. Área ocupada com soja e perda de solo no cerrado piauiense, plantios convencional e direto, safras 2000/2001 e 2007/2008

\begin{tabular}{c|c|c|c}
\hline Safras & Área ocupada $^{l}$ (ha) & $\begin{array}{c}\text { Erosão no plantio } \\
\text { convencional }^{2} \text { (t/ano) }\end{array}$ & $\begin{array}{c}\text { Erosão no plantio } \\
\text { direto }^{2} \text { (t/ano) }\end{array}$ \\
\hline $2000 / 2001$ & 62.000 & 620.000 & 496.000 \\
$2007 / 2008$ & 253.600 & 2.536 .000 & 2.028 .800 \\
\hline
\end{tabular}

Fonte: Conab (2008) ${ }^{1}$; Calculada com base nos dados de Dedecek et al (1986) ${ }^{2}$.

Nas safras consideradas, as perdas físicas de solos nos plantios convencional e direto de soja foram de $10 \mathrm{t} / \mathrm{ha} / \mathrm{ano}$ e $8 \mathrm{t} / \mathrm{ha} / \mathrm{ano}$, respectivamente. Identificou-se que o plantio convencional gerou erosão $25 \%$ superior ao direto, evidenciando-se a relevância desta tecnologia para a sustentabilidade do manejo do solo.

Nessa perspectiva, Correia et al. (2004) ressaltam que o grande desafio para a agricultura reside em elevar a produtividade ao invés de acrescer a área ocupada, minimizando a degradação dos solos. No cerrado piauiense, a despeito do crescimento da produtividade no dito período, de $36,43 \%$, percebeu-se que, em ternos percentuais, a expansão da área cultivada foi 8,4 vezes maior, indicando que a inclusão de novas terras ocorreu em um ritmo superior ao do maior rendimento por hectare. $\mathrm{O}$ conjunto dos resultados da pesquisa encontrase na Tabela 2. 
626 - Valoração Econômica dos Efeitos Internos da Erosão: Impactos da Produção de Soja no Cerrado Piauiense

Tabela 2. Total dos custos internos causados pela erosão dos solos, a preços constantes, em reais, em plantios convencional e direto, no cerrado piauiense, para as safras 2000/2001 e 2007/2008

\section{Safra 2000/2001}

\begin{tabular}{c|c|c}
\hline Sistemas de plantios & Custo de reposição & Custo por hectare \\
\hline Convencional & $1.423 .628,95$ & 22,96 \\
Direto & $1.360 .098,12$ & 21,93 \\
\hline
\end{tabular}

Safra 2007/2008

\begin{tabular}{c|c|c}
\hline Sistemas de plantios & Custo de reposição & Custo por hectare \\
\hline Convencional & $5.682 .924,00$ & 22,40 \\
Direto & $5.376 .292,80$ & 21,20 \\
\hline
\end{tabular}

Fonte: Elaborada a partir das tabelas nos anexos A,B,C,D,E e F.

De acordo com a referida Tabela, verificou-se que, em plantio convencional, na safra 2007/2008, o Custo de Reposição (CR) foi de R $\$$ $5.682 .924,00$, incremento de $299,18 \%$ em relação ao montante de $\mathrm{R} \$$ $1.423 .628,95$ da safra 2000/2001. O acréscimo entre as safras para o plantio direto foi de $295,28 \%$, significando que o $C R$ passou de $R \$ 1.360 .098,12$ para $\mathrm{R} \$ 5.376 .292,80$.

Com base no cenário descrito, percebeu-se uma inversão quanto ao custo por hectare, haja vista o decréscimo entre as safras 2007/2008 e 2000/2001 ter sido de $2,43 \%$ e $3,32 \%$ para os plantios convencional e direto, respectivamente.

Todavia, notabiliza-se que esta discrepância é apenas aparente, uma vez que, em termos absolutos, refletiu o aumento médio nos preços dos fertilizantes, de $102 \%$, e a ampliação da área ocupada, de $309 \%$, no período sob análise. Alicerçado em Marques (1998), esta conformação derivou do fato de o método ser altamente sensível ao comportamento dos preços dos fertilizantes no mercado.

Ademais, destaca-se a assertiva de Merico (2002), de que o Método Custo de Reposição aufere os gastos necessários para repor a capacidade produtiva de um recurso danificado, denominados de valor da degradação ambiental. Assim, os CRs consistem nos valores reais, a preço de mercado, de alternativas tecnológicas capazes de mitigar ou restaurar serviços ambientais eventualmente destruídos, provocando a diminuição do fluxo desses serviços. Por conseguinte, modificações bruscas nas estimativas da valoração, não implicam, 
necessariamente, alterações na qualidade ambiental, mas sim, a expressão econômica do dano.

Não obstante a safra 2007/2008 ter apresentado valores absolutos superiores para os CRs, o custo por hectare constituiu-se como o mais apropriado como indicador ambiental de degradação dos solos, devido ao fato de relativizar o comportamento dos CRs com a área ocupada que, nesse ínterim, passou de 62.000 para 253.600 hectares. Consequentemente, assevera-se que o custo por hectare foi menor em decorrência da acessão mais que proporcional da área ocupada de 309\% em relação ao acréscimo dos CRs de 299,18\% e 295,28\%, para os plantios convencional e direto, respectivamente. Esta conformação exprimiu que, entre as safras analisadas, constatou-se a redução relativa dos dispêndios essenciais para manter a produtividade dos solos cultivados com soja no cerrado piauiense.

Por tratar-se de estudo pioneiro sobre a região, não existem outras estimativas disponíveis para comparação direta, logo, os CRs expostos na Tabela 2 são indicativos de grandeza das repercussões econômicas relativas à erosão na região. Nessa perspectiva, no intuito de expressar a relevância dos danos causados e a inevitabilidade de sustentar a produtividade dos solos, comparouse os resultados obtidos com o valor da produção de soja no Piauí para ambos os períodos e sistemas de plantios. Como o valor da produção de soja consoante IBGE (2008), a preços constantes ${ }^{5}$, para a safra 2000/2001 foi de $R \$$ 45.594.862,71, para recuperar os nutrientes carreados pela erosão dos solos, foram requeridos $3,12 \%$, que correspondem a $R \$ 1.423 .628,95$ e $2,98 \%$, que equivaleram a $\mathrm{R} \$ 1.360 .098,12$ do valor da produção, para os plantios convencional e direto. Por outro lado, como o valor da produção de soja na safra 2007/2008 foi de $\mathrm{R} \$ 198.520 .000,00$, destes, $2,8 \%$ e 2,7\% representaram $\mathrm{R} \$ 5.682 .924,00$ e $\mathrm{R} \$ 5.376 .292,00$ para os plantios convencional e direto, respectivamente, e consubstanciaram-se nos custos ambientais advindos da produção de soja.

Destarte, em média, os custos internos de reposição da fertilidade em razão do processo erosivo corresponderam a 2,9\% do valor da produção de soja ao ano, inclusive porque conforme Comune \& Marques (1997), danos físicos em ativos produtivos, ocasionados por alterações no meio ambiente, constituem degradações que, traduzido em termos monetários, refletem os prejuízos ou os custos que a sociedade está suportando, o que significa que tais dispêndios integram o custo social da produção de soja.

\footnotetext{
5 Como o valor da produção no referido período foi de $\mathrm{R} \$ 25.562 .000,00$, para atualizá-lo, utilizou-se o INPC, com base em dezembro de 2008, obtendo-se o seguinte resultado: $25.562 .000 \times 1,783697=\mathrm{R} \$ 45.594 .862,71$.
} 
628 - Valoração Econômica dos Efeitos Internos da Erosão: Impactos da Produção de Soja no Cerrado Piauiense

Enfatiza-se, ainda em consonância com Marques \& Pereira (2004), que os danos ambientais causados pelo processo de erosão do solo encerram efeitos internos e externos à área de produção agrícola, porém, em virtude de este estudo debruçar-se somente sobre a obtenção dos efeitos internos, diversos impactos geradores de custos ambientais não foram objeto de valoração, como os valores de opção, de existência e demais valores de uso, componentes do Valor Econômico Total.

Contudo, a despeito das limitações das estimativas, reconheceu-se que os resultados obtidos consistiram em avanço no sentido de proporcionar, em geral, objetividade às discussões relativas à conservação dos solos e, em particular, o custo de deterioração dos solos no cerrado piauiense.

Por meio da pesquisa constatou-se a supremacia do sistema de plantio direto enquanto alternativa sustentável ao plantio convencional, devido ao fato de o controle da erosão requerer menor custo de reposição de nutrientes, haja vista que nas safras 2000/2001 e 2007/2008 os CRs de plantio convencional foram $4,6 \%$ e $5,7 \%$, respectivamente, maiores que no sistema direto. Esta realidade demonstrou que a valoração da degradação do solo, calculada com base no método de Custo Reposição é importante indicador de sustentabilidade quando utilizado como parâmetro de comparação entre o sistema convencional e direto de produção agrícola, no sentido de apontar claramente as vantagens econômicas e ambientais específicas de cada sistema.

$\mathrm{Na}$ avaliação da eficiência dos sistemas de plantio convencionais e conservacionistas, agricultores se norteiam pelos custos de implantação de curto prazo, os quais normalmente são maiores para o plantio direto por omitirem os passivos ambientais implícitos. Assim, as alternativas conservacionistas apresentam-se como viáveis mediante análise custo-benefício de longo prazo, o que as tornam dissonantes dos critérios imediatistas de rentabilidade do agronegócio. De acordo com Leite (2009), apesar dos benefícios ambientais e socioeconômicos do plantio direto, verificou-se no cerrado do Meio Norte o predomínio do manejo do solo convencional, por isso, acreditou-se que os valores dos CRs do cerrado piauiense, alusivos a tal sistema de plantio, foram os mais próximos da realidade.

Por conseguinte, esse cenário revelou quão importante é a mensuração dos gastos de reposição da capacidade produtiva do solo do cerrado piauiense, no sentido de despertar para a conscientização de inserção de investimentos para a conservação do solo, bem como para a elaboração de mecanismos econômicos que favoreçam a capacidade de suporte dos recursos naturais, notadamente, solos e recursos hídricos. Logo, torna-se premente a criação de 
um banco de dados agregado pelo Ministério do Meio Ambiente e Secretaria Estadual do Meio Ambiente e Recursos Hídricos, órgãos responsáveis pela promoção, adoção de princípios e estratégias para o conhecimento, proteção e recuperação do meio ambiente, abrangendo diferenciadas culturas, de variadas áreas e tipos de solo, para subsidiar as ações que tratam das questões ambientais nas distintas esferas de governo e na iniciativa privada, na formulação de políticas que promovam a estagnação do processo erosivo e a integridade de áreas agrosilvopastoris com potencial para degradar. Nesse sentido, estudos adicionais são imprescindíveis, tanto para desvendar os valores monetários necessários a um programa de conservação, quanto para identificação e quantificação mais ampla dos danos ao meio ambiente e revelação dos valores econômicos associados.

\section{Referências Bibliográficas}

CAMPOS, E. M. G. Valoração econômica da erosão do solo: metodologia e estudo de caso para o município de Lagoa Dourada / MG. COPPE / UFRJ, Tese de Doutorado, 2000.

COMUNE, A. E; MARQUES, J. F . Custo ambiental: impactos econômicos dos sedimentos na geração de energia elétrica. Revista de Economia Aplicada, São Paulo, p. 99-113, 1997.

CONAB. Companhia Nacional de Abastecimento. 2008. Disponível em: $<$ http:/ /www.conab.gov.br/conabweb/index.php?PAG=101>. Acesso em 20/01/2008.

CORREIA, J. R; REATTO, A; SPERA, S. T. Solos e suas relações com o uso e o manejo. In: SOUSA, D.M.G; LOBATO, E. (Ed). Cerrado: correção do solo e adubação. 2. ed. Brasília: Embrapa Informação Tecnológica, 2004.

DEDECEK, R. A; RESCK, D.V. S; FREITAS JÚNIOR, E. et al. Perdas de solo, água e nutrientes por erosão em latossolo vermelho escuro dos cerrados e de manejo da palhada do milho. Revista Brasileira de Ciência do Solo. Documento, 64. Campinas, v.10, p. 265-272, 1986.

DINIZ, B. P. C. O Grande Cerrado do Brasil Central: geopolítica e economia. São Paulo: Universidade de São Paulo, Programa de pós-graduação em geografia humana, Tese de Doutorado, 2007. 
630 - Valoração Econômica dos Efeitos Internos da Erosão: Impactos da Produção de Soja no Cerrado Piauiense

DOBEREINER, J. Microbiologia, uma bactéria para a agricultura. In: Ciência Hoje, v. 10, n. 55, p. 0-16, 1989.

FUNDAÇÃO CEPRO. Cerrados piauienses. Teresina, 1992.

IBGE. Para compreender o INPC: um texto simplificado. Rio de Janeiro, 2006.

IBGE. Sistema IBGE de Recuperação Automática-SIDRA. Produção Agrícola Municipal. Disponível em:<http://www.sidra.ibge.gov.br $>$. Acesso em: 02/12/ 2008.

LEITE, L. F. C. Sistema de plantio direto: opção para solos dos cerrados do meio norte? 2006. Disponível em: $\leq$ http://www.paginarural.com.br/artigos/l> . Acesso em: 01 de fevereiro de 2009.

MARQUES, J. F. Custos da erosão do solo em razão dos efeitos internos e externos à área da produção agrícola. In: Revista de Economia e Sociologia Rural, vol. 36, nº 1, jan. / mar. Brasília: SOBER, 1998.

MARQUES, J. F; PEREIRA, L. C. Valoração econômica dos efeitos da erosão: estudo de caso em baciashidrográficas .Jaguariúna: Embrapa Meio Ambiente, 2004.

MERICO, L. F. K. Introdução à economia ecológica. Blumenau, Ed. da FURB, 2002.

OLIVEIRA, A. U. de. A Geografia agrária e as transformações territoriais recentes no campo brasileiro. In: CARLOS, A. F. A (org). Novos Caminhos da Geografia. São Paulo: Contexto, 2002.

REZENDE, P. M. de, LIMA, L.A. P., JUNQUEIRA NETTO, A. et al. Efeito de doses de inoculantes sobre a nodulação e produção de grãos de soja (Glycine max (L.) Merril). In:Seminário nacional de soja 2., Brasília, 1981. Brasília: EMBRAPA. p. 573-582, 1981. 


\section{ANEXO A}

Valor econômico do custo de reposição de nutrientes da produção de soja, plantio convencional, no cerrado piauiense, na safra 2000/2001

\begin{tabular}{|c|c|c|c|c|c|c|c|}
\hline Nutrientes & $\begin{array}{l}\text { Concentração } \\
\text { de nutrientes no } \\
\text { solo }(\%)^{*}\end{array}$ & $\begin{array}{l}\text { Perdas de } \\
\text { nutrientes } \\
\text { (ton.) }\end{array}$ & Fertilizantes & $\begin{array}{l}\mathrm{Kg} \\
\text { fertilizante } \\
/ \mathrm{Kg} \\
\text { nutrientes }\end{array}$ & $\begin{array}{l}\text { Perdas de } \\
\text { fertilizantes } \\
\text { (t/ano) }\end{array}$ & $\begin{array}{l}\text { Preço de } \\
\text { fertilizante } \\
\text { (R\$) ** }\end{array}$ & $\begin{array}{l}\text { Valor econômico de } \\
\text { reposição (R\$/ano) }\end{array}$ \\
\hline Fósforo & 0,002614 & 16,37 & $\begin{array}{l}\text { Superfosfato } \\
\text { simples }\end{array}$ & 5,56 & 91,02 & 450,00 & $40.959,00$ \\
\hline Potássio & 0,010058 & 62,35 & $\begin{array}{l}\text { Cloreto de } \\
\text { potássio }\end{array}$ & 1,72 & 107,24 & 630,00 & $67.561,20$ \\
\hline $\begin{array}{l}\text { Cálcio + } \\
\text { Magnésio }\end{array}$ & 0,094872 & 588,20 & $\begin{array}{l}\text { Calcário } \\
\text { dolomítico }\end{array}$ & 2,63 & $1.546,97$ & 45,00 & $69.613,65$ \\
\hline $\begin{array}{l}\text { Perda de solo } \\
\text { em Ton. (a) }\end{array}$ & 620.000 & - & - & - & - & - & $178.133,85$ \\
\hline $\begin{array}{l}\text { Custo de } \\
\text { aplicação (b) }\end{array}$ & - & - & - & - & - & - & $372.000,00$ \\
\hline FBN (c) & - & - & - & - & - & - & $248.000,00$ \\
\hline $\begin{array}{l}\text { Valor total }(\mathrm{a}+ \\
\text { Valor atualiza }\end{array}$ & $\begin{array}{l}b+c) \\
\text { lo (Dez/2008)*** }\end{array}$ & & & & & & $\begin{array}{c}798.133,85 \\
1.423 .628,95\end{array}$ \\
\hline
\end{tabular}

Fonte: (*) Marques (1998); (**) Pesquisa direta realizada no mercado; (***) Fator de atualização INPC segundo IBGE (2006): 1,783697

\section{ANEXO B}

Valor econômico do custo de reposição de nutrientes da produção de soja, plantio direto, no cerrado piauiense, na safra 2000/2001

\begin{tabular}{|c|c|c|c|c|c|c|c|}
\hline Nutrientes & $\begin{array}{l}\text { Concentração } \\
\text { de nutrientes } \\
\text { no solo }(\%)^{*}\end{array}$ & $\begin{array}{l}\text { Perdas de } \\
\text { nutrientes } \\
\text { (ton.) }\end{array}$ & Fertilizantes & $\begin{array}{l}\mathrm{Kg} \\
\text { fertilizante } \\
/ \mathrm{Kg} \\
\text { nutrientes }\end{array}$ & $\begin{array}{l}\text { Perdas de } \\
\text { fertilizantes } \\
\text { (t/ano) }\end{array}$ & $\begin{array}{l}\text { Preço de } \\
\text { fertilizante } \\
(\mathrm{R} \$)^{* *}\end{array}$ & $\begin{array}{l}\text { Valor } \\
\text { econômico de } \\
\text { reposição } \\
\text { (R\$/ano) }\end{array}$ \\
\hline Fósforo & 0,002614 & 13,10 & $\begin{array}{l}\text { Superfosfato } \\
\text { simples }\end{array}$ & 5,56 & 72,84 & 450,00 & $32.778,00$ \\
\hline Potássio & 0,010058 & 49,88 & $\begin{array}{l}\text { Cloreto de } \\
\text { potássio }\end{array}$ & 1,72 & 85,79 & 630,00 & $54.047,70$ \\
\hline $\begin{array}{l}\text { Cálcio + } \\
\text { Magnésio }\end{array}$ & 0,094872 & 470,56 & $\begin{array}{l}\text { Calcário } \\
\text { dolomítico }\end{array}$ & 2,63 & $1.237,57$ & 45,00 & $55.690,65$ \\
\hline $\begin{array}{l}\text { Perda de solo } \\
\text { em ton. (a) }\end{array}$ & 496.000 & - & - & - & - & - & $142.516,35$ \\
\hline $\begin{array}{l}\text { Custo de } \\
\text { aplicação (b) }\end{array}$ & - & - & - & - & - & - & $372.000,00$ \\
\hline FBN (c) & - & - & - & - & - & - & $248.000,00$ \\
\hline \multirow{2}{*}{\multicolumn{7}{|c|}{$\begin{array}{l}\text { Valor total }(\mathrm{a}+\mathrm{b}+\mathrm{c}) \\
\text { Valor atualizado }(\text { Dez } / 2008) * * *\end{array}$}} & $762.516,35$ \\
\hline & & & & & & & $1.360 .098,12$ \\
\hline
\end{tabular}

Fonte: (*) Marques (1998); (**) Pesquisa direta realizada no mercado (2009); (***) Fator de atualização INPC segundo IBGE (2006): 1,783697 
632 - Valoração Econômica dos Efeitos Internos da Erosão: Impactos da Produção de Soja no Cerrado Piauiense

\section{ANEXO C}

Valor econômico do custo de reposição de nutrientes da produção de soja, plantio convencional, no cerrado piauiense, na safra 2007/2008

\begin{tabular}{|c|c|c|c|c|c|c|c|}
\hline Nutrientes & $\begin{array}{l}\text { Concentração } \\
\text { de nutrientes } \\
\text { no solo }(\%)^{*}\end{array}$ & $\begin{array}{l}\text { Perdas de } \\
\text { nutrientes } \\
\text { (ton.) }\end{array}$ & Fertilizantes & $\begin{array}{l}\mathrm{Kg} \\
\text { fertilizante/ } \\
\mathrm{Kg} \\
\text { nutrientes }\end{array}$ & $\begin{array}{l}\text { Perdas de } \\
\text { fertilizantes } \\
\text { (Ton/ano) }\end{array}$ & $\begin{array}{l}\text { Preço de } \\
\text { fertilizante } \\
\text { (R\$)** }\end{array}$ & $\begin{array}{l}\text { Valor } \\
\text { econômico de } \\
\text { reposição } \\
\text { (R\$/ano) }\end{array}$ \\
\hline Fósforo & 0,002614 & 66,98 & $\begin{array}{c}\text { Superfosfato } \\
\text { simples }\end{array}$ & 5,56 & 372,40 & 640,00 & $238.336,00$ \\
\hline Potássio & 0,010058 & 255,07 & $\begin{array}{l}\text { Cloreto de } \\
\text { potássio }\end{array}$ & 1,72 & 438,60 & $1.800,00$ & $789.480,00$ \\
\hline $\begin{array}{l}\text { Cálcio + } \\
\text { Magnésio }\end{array}$ & 0,094872 & $2.405,95$ & $\begin{array}{l}\text { Calcário } \\
\text { dolomítico }\end{array}$ & 2,63 & $6.327,65$ & 80,00 & $506.212,00$ \\
\hline $\begin{array}{l}\text { Perda de solo } \\
\text { em ton. (a) }\end{array}$ & 2.536 .000 & - & - & - & - & - & $1.534 .028,00$ \\
\hline $\begin{array}{l}\text { Custo de } \\
\text { aplicação (b) }\end{array}$ & - & - & - & - & - & - & $2.282 .400,00$ \\
\hline FBN (c) & - & - & - & - & - & - & $1.866 .496,00$ \\
\hline Valor total $(\mathrm{a}+$ & $+\mathrm{c})$ & & & & & & $5.682 .924,00$ \\
\hline
\end{tabular}

Fonte: (*) Marques (1998); (**) Pesquisa direta realizada no mercado (2009).

\section{ANEXO D}

Valor econômico do custo de reposição de nutrientes da produção de soja, plantio direto, no cerrado piauiense, na safra 2007/2008

\begin{tabular}{|c|c|c|c|c|c|c|c|}
\hline Nutrientes & $\begin{array}{l}\text { Concentração } \\
\text { de nutrientes } \\
\text { no solo }(\%)^{*}\end{array}$ & $\begin{array}{l}\text { Perdas de } \\
\text { nutrientes } \\
\text { (ton.) }\end{array}$ & Fertilizantes & $\begin{array}{l}\mathrm{Kg} \\
\text { fertilizante/ } \\
\mathrm{Kg} \\
\text { nutrientes }\end{array}$ & $\begin{array}{l}\text { Perdas de } \\
\text { fertilizantes } \\
\text { (Ton/ano) }\end{array}$ & $\begin{array}{l}\text { Preço de } \\
\text { fertilizante } \\
\text { (R\$)** }\end{array}$ & $\begin{array}{l}\text { Valor } \\
\text { econômico de } \\
\text { reposição } \\
\text { (R\$/ano) }\end{array}$ \\
\hline Fósforo & 0,002614 & 53,58 & $\begin{array}{c}\text { Superfosfato } \\
\text { simples }\end{array}$ & 5,56 & 297,90 & 640,00 & $190.662,40$ \\
\hline Potássio & 0,010058 & 204,06 & $\begin{array}{l}\text { Cloreto de } \\
\text { potássio }\end{array}$ & 1,72 & 350,98 & $1.800,00$ & $631.764,00$ \\
\hline $\begin{array}{l}\text { Cálcio + } \\
\text { Magnésio }\end{array}$ & 0,094872 & $1.924,76$ & $\begin{array}{l}\text { Calcário } \\
\text { dolomítico }\end{array}$ & 2,63 & $5.062,12$ & 80,00 & $404.970,40$ \\
\hline $\begin{array}{l}\text { Perda de solo } \\
\text { em ton. (a) }\end{array}$ & 2.028 .800 & - & - & - & - & - & $1.227 .396,80$ \\
\hline $\begin{array}{l}\text { Custo de } \\
\text { aplicação (b) }\end{array}$ & - & - & - & - & - & - & $2.282 .400,00$ \\
\hline FBN (c) & - & - & - & - & - & - & $1.866 .496,00$ \\
\hline \multicolumn{7}{|c|}{ Valor total $(\mathrm{a}+\mathrm{b}+\mathrm{c})$} & $5.376 .292,80$ \\
\hline
\end{tabular}

Fonte: (*) Marques (1998); (**) Pesquisa direta realizada no mercado (2009). 


\section{ANEXO E}

Custo da Fixação Biológica de Nitrogênio no cultivo de soja, em reais por hectare, no cerrado piauiense, nas safras 2000/2001 e 2007/2008

\begin{tabular}{c|c|c|c|c}
\hline Safras & $\begin{array}{c}\text { Área plantada } \\
\text { (ha) }\end{array}$ & $\begin{array}{c}\text { Quantidade de } \\
\text { inoculante* } \\
\text { (doses) }\end{array}$ & $\begin{array}{c}\text { Preço de } \\
\text { mercado } \\
\text { (Pn) (R\$) }\end{array}$ & Valor (R\$) \\
\hline $2000 / 2001$ & 62.000 & 124.000 & 2,00 & $248.000,00$ \\
$2007 / 2008$ & 253.600 & 507.200 & 3,68 & $1.866 .496,00$ \\
\hline
\end{tabular}

* Dose de $200 \mathrm{~g}$ para cada $50 \mathrm{~kg}$ de sementes, sendo necessárias duas doses por hectare. Fonte: Elaboração própria segundo os parâmetros de Resende et al (1981).

\section{ANEXO F}

Custo total de aplicação de fertilizantes, a preços correntes em reais, no cerrado piauiense, nas safras 2000/2001 e de 2007/2008

\begin{tabular}{c|c|c|c}
\hline Safras & $\begin{array}{c}\text { Área de aplicação } \\
\text { (ha) })^{1}\end{array}$ & $\begin{array}{c}\text { Custo de aplicação } \\
\text { por ha }{ }^{2}(\mathrm{R} \$)\end{array}$ & $\begin{array}{c}\text { Custo de } \\
\text { aplicação total } \\
\text { (R\$) }\end{array}$ \\
\hline $2000 / 2001$ & 62.000 & 6,00 & $372.000,00$ \\
$2007 / 2008$ & 253.600 & 9,00 & $2.282 .400,00$ \\
\hline
\end{tabular}

Fonte: Conab (2008) ${ }^{1}$; Indicador técnico embasado em Oliveira (2004) e coletado junto à empresa PAT-VAT consultoria agrícola, valores referentes a dezembro de 2000 a $2008^{2}$. 